\title{
Studies on the Renewal Problems and Countermeasures of Shengli District in Yantai
}

\author{
Chenghua Fu \\ Department of Architecture, Linyi University, Linyi, Shandong, China \\ 2857867426@qq.com
}

\begin{abstract}
Keywords: City renewal; Countermeasures; Humanistic spirit; Shengli District
\end{abstract}
\begin{abstract}
With the city expanding, increasing population, function facilities of the Old town can not meet the current economic development and improving living standard requirements of people. The transformation of the old city aims to make urban functions more perfect, more suitable for needs of the people's life, so that the city's image can been promoted. Therefore, urban renewal has become an inevitable product of urbanization. But now there are many problems existed in the process of urbanization. Therefore, how to conduct scientific and rational renovation and modernization of the old city becomes a major issue and social problem in the urbanization. Based on the reconstruction of Shengli District in Yantai, this article discussed the necessity and significance of its renewal and the problems existed in the project, then put forward some countermeasures, such as Selecting Sun Demolition modes - Demolition people-oriented; Opening source throttling to ensure the funds need in the old town environment improvement; Inheriting humanistic spirit, and develop on the basis of protecting the historical and cultural heritage and so on.
\end{abstract}

\section{Introduction}

The city is the crystallization of human civilization, human dreams and hopes of the sustenance. It has brought to mankind human endless prosperity and dreams, and also brings a lot of problems and confusion. With the development of social economy, the speeding up of urbanization, unceasing expanding of urban scale, the function of the old town facilities already can not adapt to the current economic development and people's improving living standards. Old obsolete infrastructures, unreasonable layout, increasingly prominent phenomenon, such as environmental degradation, become the bottleneck in the urbanization [1]. Therefore, the old city reconstruction project becomes inevitable product of social and economic development of urbanization.

However, the transformation of the old urban has always been the most complex social engineering and involves a wide range such as government, social, economic and other aspects and faces many contradictions and challenges. Transformation of the old city is not isolated problems, instead of the old city from the city function, layout, industrial structure adjustment, the old city can be perfect, meet the requirements of urban sustainable development [2]. In this paper, Shengli District transformation project, for example, summed up its presence in the transformation process of the problem and be improved. Based on the transformation project of Shengli District, this paper summarized the problems in the transformation process and studied the measures to improve it.

\section{Summary of the Urban Renewal}

The Connotation of Urban Renewal. The so-called urban renewal is to adjust and change the existing urban environment, internal functions, architecture, space, environment etc. to meet the requirements of urban development and urban life, for the necessary adjustments and changes. It is a choice to preserve, protect and pass a variety of ways to improve the environmental quality in work, including redevelopment, remediation, and preservation three aspects [3]. Redevelopment is based on the overall urban planning, completely changing of large-scale urban renewal of built-up areas; 
Repairing is based on the overall urban planning, urban renewal construction partly changed the original appearance of the medium-sized city; protection is based on the urban planning, the original city reconstruction in the face of small-scale.

The Importance of Urban Renewal in the Urbanization Process. (1)Urban renewal is helpful to promote the urban land resource optimal allocationDue to the huge amount of popular, under the background of urbanization and modernization development, positive and effective urban renewal is helpful to promote the optimal allocation of urban land resources, it is also of great significance for realizing the fundamental goal of old city reconstruction [4]. At the same time, the urban land resource optimal allocation for realizing the fundamental goal of old city reconstruction is of great significance. (2)Urban renewal is helpful to improve the urban functions and people's living standardsFor a long time, because of lack of scientific guidance to urban planning and construction and urban management, a lot of residents living in the places where living facilities don't match for a long time. The aim of urban renewal is to improve citizens' living conditions and let the people share the fruits of economic and social development. (3)Urban renewal is advantageous to the city's economic development and industrial structure adjustment. Urban renewal reconstruction project contains a lot of business opportunities, it not only can activate and driving the development of the surrounding commercial, also makes the old city transformation and the benign interaction between social and economic development and industrial structure adjustment, which is benefit to the optimization of the city overall layout and the promotion of urban real value. (4)Urban renewal is helpful to build the city brand and promote the urban image [5]. Combined with the urban renewal, urban functions will be improved, urban image will be promoted. Social resources can be obtained, recomposed and integrated to strengthen urban public service ability, improve the competitiveness of the city, create city brand and realize the comprehensive coordinated sustainable development of cities.

\section{Shantytown Renovation Project Introduction of Shengli District in Yantai.}

Shengli District transformation project site is located south of the Cultural Square, west of Victory Road, east of Southwest River Road, south of Jianchang Street. It is the largest and most imposed last piece of the mass of existing squatter settlements, and also is the largest and most important of Yantai City redevelopment project. Because Qicheng history block is in the east and it is adjacent to southern road of the city, it has a huge influence on urban landscape. Its settlement area is $27 \times 104 \mathrm{~m}^{2}$, a total of 3765 residents, including 3535 residential, non-residential 230.

According to the district sheet planning conditions, urban complex will be built here, making landscape of open port construction as a whole. Shengli District transformation project is divided into two blocks from north to south by a planning east-west road, the north land for commercial, office, hotel, and south land for residential, commercial, office are making into a "Mosaic" city as a whole. Shengli District is located on the west of Qishan City built in Ming Dynasty. Due to the building of Victory Road, the walls and four doors were demolished in 1956.With the development and construction of the city, winning district in the peripheral structure disappeared, leaving only part of the walls of the ruins. some streets landscape and folk buildings also retain the original style of the Qing Dynasty. Two inside construction planning, the people's bank of China and the Christian church will be maintained.

Residential housing levy of Shengli District implements monetary compensation and property rights exchange compensation. Building property right includes the in situ housing transfer or ex situ housing transfer. The average price of real estate price is 9,224 yuan/ square meter; As being levied chooses property rights exchange, a department of plan hair temporary relocation costs RMB 10800 / year or to provide temporary turnover housing; Property rights exchange is located in the housing for victory plot (plan), the area of about $61 \mathrm{~m}^{2}[6]$. 


\section{The Problems Existing in the Reform of Shengli District in Yantai}

High Proportion of Government Subsidies Has Led to the Financial Pressure. Because the residents of Shengli District are mostly low-income people, the government needs to increase the funds for demolition compensation, the old city construction and infrastructure development in the process of transformation of the old city. The government has invested nearly two hundred million in this project, which has brought a lot of pressure to the government departments.

Paying Attention to Commercial Interests and Neglecting Social Gustice and the Interests of Residents in the Removal Process. The district is a concentrated area of low-income people in Yantai. The residential area is less than $45 \mathrm{~m}^{2}$ in 1805 households, which is $51 \%$ of the total. The original residential area of $45 \mathrm{~m}^{2}$ can be the replacement of $61 \mathrm{~m}^{2}$ resettlement housing, and the minimum apartment layout is $65 \mathrm{~m}^{2}$ in the resettlement housing of property rights [7]. Should the local integration required in accordance with the price fetched Built in padded post, and other fees charged residential property management fees. Should choose monetary compensation at the same location purchase, due to the high quality, the surrounding real estate is expensive. Relocation compensation is far less than the land purchase in the same location, which results in the relocation of a passive majority of the population.

A Big Obstacle Existed in the Promoting Transformation. In the urban renewal process, resettlement and social stability become the biggest bottlenecks constraint to promote urban renewal. In the urban renewal development process, weak supervision results in long schedule, fast demolition, slow construction, more slow moving back. Since the release of monetary compensation for expropriated house is not in accordance with the announcement of similar real estate market prices, it caused certain interest losses and discontent among the masses.

The Contradiction between Protection and Development and Utilization of History. Since the deepening of the reform is still in process, the loss of the city's historical and cultural development mechanisms and social consciousness are still significant shortcomings and deficiencies, which is characteristic of the loss of the city [8]. Although retaining the People's Bank of China, the two Christian churches in the Qing Dynasty folk architecture in the transformation, street culture with Yantai features, has not been retained, which has destroyed the Church Hill area of the sheet into a traditional style and features.

\section{Suggestions on Transformation of Shingle District in Yantai}

Selecting Sun Demolition Modes-Demolition People-Oriented. Humane valuation compensation system should be set up and it is important to put the benefit of the dismantler in the first place. Adhere to the people-oriented and achieve harmonious demolition. Policymakers should recognize that urban renewal is not a simple development and transformation, but from the perspective of the improvement of people's livelihood, accelerating the development of the central city, improving the urban environment and the quality of life of residents.

Adhere to the principle of "benefiting the people", the maximum guarantee the interests of the residents. Government should actively coordinate the district construction, reduce the relevant taxes and resettlement housing construction costs to guarantee relocated people's benefit. Resettlement compensation will be open, fair and equitable.

Opening Source Throttling to Ensure the Funds Need in the Old Town Environment Improvement. On capital operation, we should actively introduce market mechanisms to improve the input and output efficiency. On the one hand, saving capital can be ensured through strict management. Public bidding can be used for bidding projects to reduce the project cost. On the other hand, it is important to mobilize social enterprise funds to participate in the environmental remediation of the old town [9]. The most appropriate financing model can be chosen according to a special redevelopment project. The old city reconstruction fund adopts the lever principle, through a small amount of 
investment by state-owned enterprises and government fiscal investment to attract a large number of small and medium-sized enterprise financing.

Inheriting Humanistic Spirit, and Develop on the Basis of Protecting the Historical and Cultural Heritage. The root causes of urban renewal is that its basic material function does not adapt to the new demands, but the context value contained within it does not disappear because of the use of functional backward, even more apparent [10]. It needs to analyze the value of the historical context of the region, to retain some of the concentrated expression of the city's historical development characteristic neighborhoods, streets reservations historical folk culture characteristics in urban redevelopment of Yantai and take in the transformation of the protection and renovation of the combination principle, for the continuity of historical context Yantai city and development.

Learning from the old city of Yangzhou update target "context of sustainable Old City Update", protection and development go hand in hand. Protect of old city cultural assets and local characteristics and let residents stay in the old city to avoid resettlement.

\section{Summary}

Generation of the old city is a long-term, spontaneous evolution, and gradually formed the existing pattern according to a certain way of organic growth. The transformation of the old urban construction has always been the most complex, the most widely involved social project, including the government, social, economic and other aspects of the comprehensive public work, and it is also the most concerned about major issues. The main purpose of urban renewal is to solve the present various urban issues and realize the economic sustainable development. Urban construction should be based on the characteristics of the old city to ensure the solid foundation for the rapid development of urbanization, to make people walk on the way of urban development and sharing more long-term.

\section{References}

[1] Z.Y. Jiang, X. Zhang and J.G Xu: Modern Urban Research, (2014) No.4, p.80-86.

[2] C. Wu: The Large-scale Transformation of the Old City in the Process of Social Space Reconstruction (Ph.D, Tsinghua University, China 2010), p.4

[3] L.Y. Wu: Introduction to human settlements and environmental science (Architecture and Building Press, China 2001).

[4] X.Y. Ma, Q.F. Yuan: Planners, (2009) No.5, p.57-59.

[5] Ladd B. Urban Planning and Civic Order in Germany, 1860-1914 (Harvard University Press, U.S.A.1990).

[6] Information on http://www.ythouse.com/

[7] Information on http://www1.yantai.gov.cn/cn/index.jsp

[8] H.Y. Zhang, Q. Li: Economic Forum, (2010) No.7, p.137-138.

[9] C.C Fang: The Journal of Jiangsu Administration Institute, (2012) No.4, p.68-74.

[10] Y.Q. Li: Urban planning, (1994) No.12, p.8-10. 